\title{
Structuration, Integrity And The Ethical Discourse In Organisations
}

Grant Jones, (E-mail: grant.jones@mgsm.edu.au), Macquarie University, Australia

\begin{abstract}
The approach to ethics in western corporations is to promote a single set of normative principles. Problems with the approach are presented before a more realistic approach is outlined.
\end{abstract}

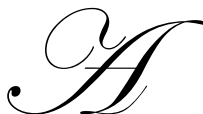
cademics with an interest in ethics have often incited business schools to place ethics at the core of business curriculum (Theis 1998; Bok 2003). The call has also been taken up in public discourse within the popular press (Browning 2003; Kolkata 2003; Alsop 2005). Such calls are based on the assumption that learning about ethics will make business leaders more ethical in their judgements and decision making. Such writings define the problem and the urgency by citing the cases of recent spectacular cases of corporate behaviour which are manifestly not ethical, such as the cases of Enron and the Australian Wheat Board. Business education is seen as an important means by which scandalous behaviours and the destruction to productivity and welfare that they course might be addressed. However, teaching ethics and teaching about ethics are two different things. The desire to transform executives into more ethical people presupposes a normative ethic that they will take on and which they will use transform the behaviour of the corporations that they run. It seems unlikely that executives are likely to be responsive to such preaching and even more unlikely that the normative ethic that would become the substance of this transformation could ever be identified. In addition ethics are in a constant state of flux: what is wrong today might be right tomorrow and ice versa. This paper looks at some harsh realities about ethics and finds a way through these realities to identify an approach to managing ethics which is based on the management of integrity.

The terms "morality" and "ethics" are often used interchangeably, but they are not the same conceptually. Morality most commonly defines what the individual must not do, while ethics tells the individual what s/he must do (Solomon 1994; 1998). Morality is most commonly identified with the individual (Fitzgerald and Hamilton 2006) and our view of it is flavoured by western individualism (McKenna 1999). Ethics may be constructed individually or as a set of precepts against which many individuals may identify. Both are socially constructed. For example a social taboo against sexual promiscuity is constructed in societies that see the family as the fundamental constituent upon which that society is built. Consistent with the definitions above, the taboo becomes a matter or morality not ethics. Herein lies the fundamental problem for people in general and managers in particular. A manager has some chance to manage ethically where social constructions are stable. It is simply a matter of identifying the rules and sticking to them. But how can one institute ethical practice where social constructions are not stable. Contemporary social theory sees social forms in a process of continuous structuration (see Giddens 1975, 1979; Bourdieu 1981,1986,1990; Archer 1995, 1996, 2000). That is to say that structures that guide behaviour, including high status knowledge such as ethical frameworks, are in a process of constant change.

Those who call for ethics courses tend to be naïve about the basic social forces underpinning the creation of structures such as ethical frameworks. For their calls to be enacted, we would need to presuppose a set of normative ethical principles against which people can be trained. Normative ethics have been defined as basic principles and criteria that determine what is right and wrong about any proposed action and the rights of people who are stakeholders in that action (Frankena 1973). More specifically they have been defined as involving "substantive proposals concerning how to act, how to live or what kind of person to be. In particular,[normative ethics] attempts to state and defend the most basic principles governing these matters." (Kagan 1998 2) Underpinning this definition is the assumption that normative ethics have an objective reality, are absolute and can be universally understood. They form a set of lore to which all people should conform. 
Normative ethics suffer a number of shortcomings which disqualify them as a basis for either business decision making or courses in ethical business decision making. The first is that they are largely platitudinous: too often they represent a marketing image rather than the actual ethics of the organisation. Consider the following extract:

\section{Values}

\section{Respect}

We treat others as we would like to be treated ourselves. We do not tolerate abusive or disrespectful treatment.

Ruthlessness, callousness and arrogance do not belong here.

\section{Integrity}

We work with customers and prospects openly, honestly and sincerely. When we say something, we will do it. When we say we cannot or will not do something, then we won't do it.

\section{Communication}

We have an obligation to communicate. Here we take the time to talk with one another... and to listen. We believe that information is meant to move and that information moves people.

Enron's "Code of Ethics" (extract) from www.business ethics.ca/enron/index.html accessed 27 October 2005

The language and sentiments are beautiful and were clearly sculpted by a poet. However, they have no relationship to Enron's actual behaviour.

The 2005 Annual Report of the Australian Wheat Board (which paid AUD \$300m to the Government of Saddam Hussein in bribes) says that the AWB:

"is committed to clearly promoting and demonstrating that their business affairs and operations are at all times being conducted legally, ethically and in accordance with the highest standards of integrity and propriety. ... The AWB corporate ethics and Code of Conduct is based on this principle and its observance provides the foundations upon which the company's reputation with growers, customers, suppliers and stakeholders is based." (AWB Annual Report $2005 \mathrm{pg}$ 43)

As platitudes that are ignored in reality, such ethical statements can never be tested to see whether in fact they do form a viable framework for business practice. They operate only in the world of fantasy.

This problem also illustrates the possibility that an ethical character is inconsistent with the character of the corporate structures within which we all work (Bakan 2005). Adam Smith dismisses corporate social responsibility as an affectation. He says of the business person that:

"by pursuing his own interest he frequently promotes that of society more effectually than when he really intends to promote it. I have never known such good done by those who affected to trade for the public good. It is an affectation, indeed, not very common among merchants, and very few words need to be employed in dissuading them from it." (Smith 1976).

Two hundred years later Milton Freedman drew on Adam Smith to counter calls for corporate social responsibility. Freedman argues that the only people who have the right to divert proprietor's funds to purposes other than profit are the proprietors themselves (Freedman 1989). He goes on to argue that managers as agents of these 
principals have only one responsibility and that is to increase profits. In his essay Freedman raises a fundamental dilemma that vexes the whole corporate responsibility debate: people have ethics, but corporations do not. More recently Deborah Doanne has argued that corporations must be subject to markets, and markets don't allow the corporation to do well while doing good (Doanne 2005)

However, individuals operate from many ethics, especially in a social unit which can be characterised as multi cultural. The answer to the fundamental ethical question of "what must I do" will be different for each person. This is the coup de grace for normative ethics. There is not one ethic but many. For example, some may have a work ethic; others may be motivated by family values; others may build a set of ethical principles upon their individual sense of justice. Justice in particular is a concept whose meaning has been fragmented by philosophers. The philosopher John Rawls argues that justice is whatever people regard as fair: a socially constructed concept. However, Friedich Von Hayek (1982) has argued that justice is simply a ruse to legitimate a redistribution of wealth to individuals and groups who are powerful enough to establish a spurious claim on the basis of justice. To Smith, Freedman and Von Hayek, there is no collective good because there is no such thing as society. There are only large numbers of individuals. Therefore any attempt to direct resources to a common good, inevitably benefits well placed individuals. Corporate social responsibility is therefore illusory and deceptive, and so its practice is unethical.

Whether you believe in society or not, there will always exist a tension between any set of normative ethics chosen by the corporation and the ethics from which the individual seeks to operate. The variation in ethical frames from which people in organised life operate defies simple codification into a normative ethical set. One may respond by seeking universals that some how transcend the variation and provide a unified set of principles that underpins the variation. However, such attempts are inevitably bland and unhelpful, yielding more platitudes such the oft cited "above all do no harm." Similarly, a search for role models of individuals whose behaviour is thoroughly good or thoroughly bad yields little incite. Most people could agree that Hitler was thoroughly bad and that Gandhi was thoroughly good, but what good is this to solving day to day managerial dilemmas in the corporation. Few managers arrive at work and must begin their day with a decision as to whether to emancipate or destroy a race of people.

Given these four problems with normative ethics - i.e. that they are unrepresentative of the companies true stance, that they are an anathema to the role of the corporation, that they cannot represent the varied ethics of people within the corporation, and that they generate little useful guidance to managers in making day to day business judgements - what alternative can be offered as guidance for managers?

Integrity is a benchmark against which any particular ethical stance can be taken seriously. While there is no universal set of ethics that business can be expected to adopt on mass, there is a principle of integrity that conceptualised as consistency between what one says one will do and the kind of behaviours that one actually exhibits. To have integrity does not imply abidance with any particular normative ethics, but rather an abidance with the ethic that a person uses to represent him/herself. Corporations can also be said to exhibit integrity. A bank that forecloses on a mortgage and thrusts a pensioner onto the street can be said to have integrity with respect to its published values if those values support shareholder wealth. The nastiest of people can be said to have integrity provided that they advertise the principles from which they operate. Drawing upon Machiavelli to harden the point, a person can be feared and not hated provided, s/he operates with integrity, so that his/her actions are not seen to be arbitrary.

"Nevertheless a prince ought to inspire fear in such a way that, if he does not win love, he avoids hatred; because he can endure very well being feared whilst he is not hated, which will always be as long as he abstains from the property of his citizens and subjects and from their women. But when it is necessary for him to proceed against the life of someone, he must do it on proper justification and for manifest cause, but above all things he must keep his hands off the property of others, because men more quickly forget the death of their father than the loss of their patrimony." (The Prince Chapter XVII)

This is to imply that a feared person may also be trusted, provided that person acts with integrity. 
Those who create the imagery of trying to please everyone cannot be trusted and there can be no basis for a business relationship without trust. This is especially the case where the quality of their service cannot easily be assessed before the purchase, a situation that economists describe as an "information asymmetry." Economic theory as exemplified by Adam Smith above is based on the assumption that all people are rational actors, which is to argue that they can be safely expected to act in self interest. Because it is not possible to do everything ones self, people must delegate responsibility to others to act on their behalf and in their interest.

The basic problem with this reality arises from the strength and validity of the rational actor assumption: the agent will try to act in his/her interest, not that of the principal. It becomes necessary to find a means of harnessing your agent to your own cause. One way to do this is to offer commission payments which align a successful result for the principal with a successful result for the agent. Where such arrangements operate effectively, the agent can be assumed to operate in the interests of the principle. Consider the following home page.

Figure 1 - A Mission Lacking Integrity

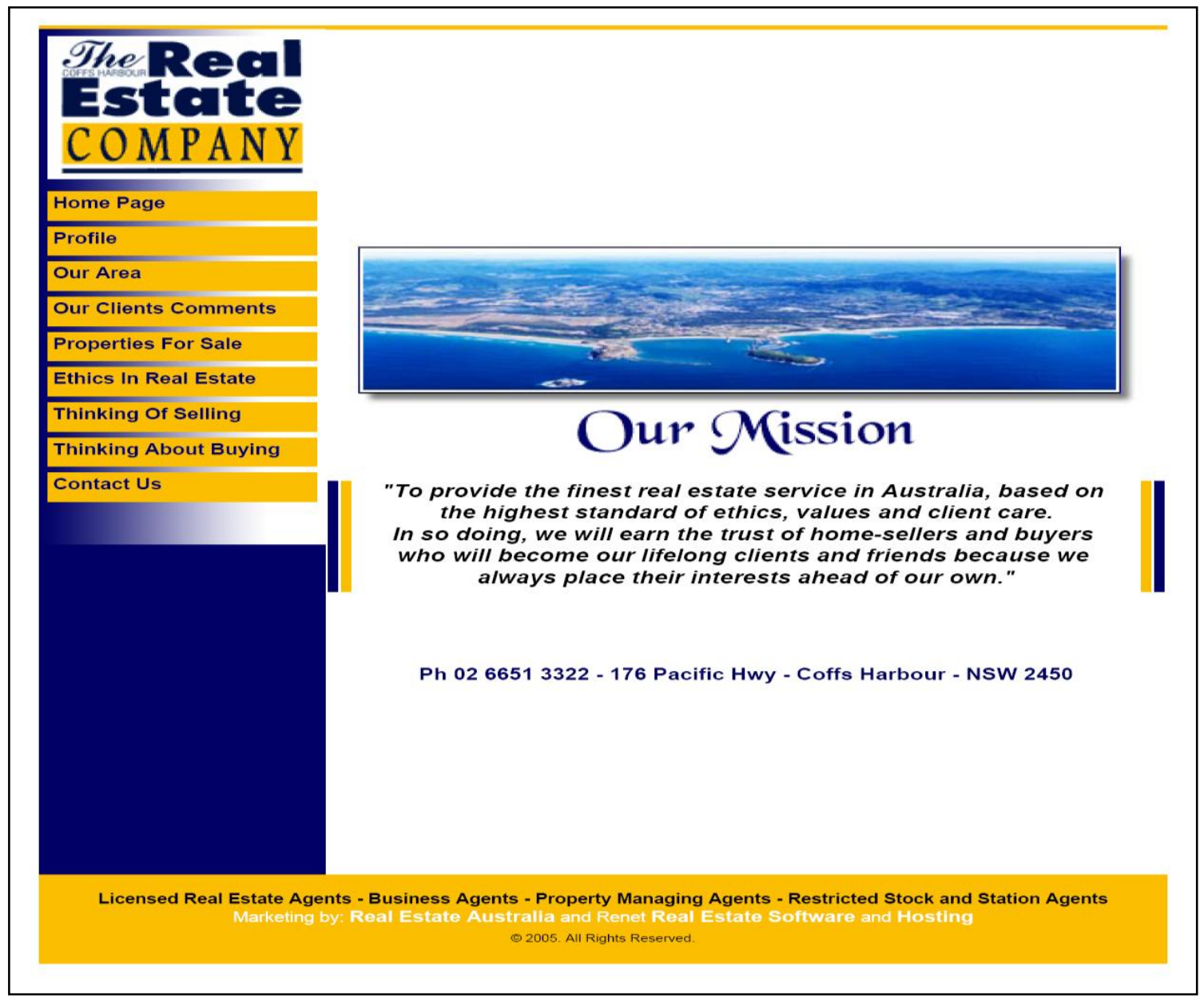

http://www.realestateco.com.au/ Accessed 11 May 2006 
Acceptance of the representation made in the mission statement in figure 1 is both theoretically and practically impossible. The advertisement lacks integrity because the agent cannot realistically service the needs of both buyer and seller. If s/he gets the highest possible price the seller, who is paying the commission, than s/he must get the worst possible deal for the buyer. In addition, it can be concluded that the agent will act for no other interest than that of the person paying the commission. If the agent takes a commission from a competing interest, $\mathrm{s} / \mathrm{he}$ cannot be acting with integrity because s/he can not service the interests of competing parties. In some countries (eg Hong Kong) agents take commission from both buyer and seller in the one transaction. Such a system cannot be said to have integrity. Nor can it be said to promote integrity.

In a multi cultural environment many different values will tend to coexist. In many cases these inconsistent values will provoke the construction of inconsistent and competing sets of ethical standards. The way to negotiate this reality is to place an expectation on people to project openly the standards by which they choose to operate, so that others can make informed choices about whether and how to engage in a business relationship. The case for integrity is that it is an enabler of business relations.

Integrity also allows that ethical precepts and norms will change from time to time and context to context. Ethical principles, like all other social norms come into being as they are enacted. When the moment of enactment passes they cease to exist. To apply Giddens (1979) theory of structuration, the ethic exists at the moment of instantiation, which is Giddens word for the way in which a social structure such as a guiding ethical principle comes into being through action and then afterwards disappears into a spectral world. It follows that as action changes, there is a modification to the structures that it brings into being.

So it is that an ethical principle will change with its use. This means that any attempt to fix and codify ethical principles will quickly become dated and obsolete as action moves ethical principles on from the ways in which they are constructed in institutionalised codes. Even where codes of conduct are developed with integrity by well meaning individuals and groups who genuinely want to capture and document the ethical standards of the group, behaviour will continuously modify those standards. As such the maintenance of integrity depends on ethics being considered a living beast that is in continual mutation. Because fixed normative standards are ineffectual as a means to manage ethical behaviour within the corporation, a more realistic management strategy is to treat ethics as a continuous discourse within the organisation and to promote continuous reflection about appropriate ethics at any point in time. A key question to ask is how do new and emerging relationships modify the ethical frameworks that had previously existed? Another implication of the mutability of ethics is that to maintain corporate integrity in dealings with outsiders, organisations must be continuously communicating who they are and accept that those communications are liable to change. Business relationships are liable to be enhanced where all stakeholders have good information at the point of contract formation about where an organisation stands.

The value of ethics within the organisation goes beyond simply marketing the organisation as a good corporate citizen. Uses of normative standards as a self promotion device are likely to be interpreted with increasing cynicism as the catalogue of companies with poetically beautiful codes of conduct but inexpressibly bad behaviour grows. The real value of ethics within a corporation is that they can enable and guide action. In the absence of a clear understanding of what is seen as right and appropriate at a given point in time people are more likely to act conservatively. Employees may reason to themselves that where doubt exists, don't try an option that is likely to be frame braking or where the ability to render an account of action is clouded by uncertainty. In such cases the manager who chooses to generate and guide a discourse on ethics, broadens the scope of what people believe they can do while clarifying the boundaries of acceptability. An ethical discourse is thus an enabler of innovation. In its turn, that innovation prompts continuous review of the collective ethics of the organisation. The organisation and the people in it are continuously considering the basic ethical question: what kind of a person/corporation do I want to enact? As new action generates altered answers to that question, the ethical framework of the organisation develops as does the scope for new action. Integrity is maintained where the discourse and the action are consistent, and that is all any person has a right to expect. 


\section{REFERENCES}

1. Alsop R. (2005) At M.B.A. Programs, Teaching Poses its Own Dilemma Wall Street Journal, 12 April 2005, p 7.

2. Archer M. (1995) Realist Social Theory: the morphogenetic approach Cambridge University Press, Cambridge.

3. Archer M. (1996) Social Integration and System Integration: developing the distinction. Sociology Vol 30 \# 4 pp 679-99.

4. $\quad$ Archer M. (2000) Being Human: the problem of agency Cambridge University Press, Cambridge.

5. Bok D. (2003) Academic Values and the Lure of Profit The Chronicle of Higher Education: the Chronicle Review Vol 49 \#30 pp30-38.

6. Bourdieu P. (1981) The genesis of the concepts of habitus and field Soicocriticism \#2 pp11-24.

7. $\quad$ Bourdieu P. (1990) In Other Words, Polity Press Cambridge.

8. Bourdieu, Pierre (1986). The Forms of Capital. In John Richardson, Ed. Handbook of Theory and Research for the Sociology of Education. New York: Greenwood Press, pp. 241-258.

9. Browning L. (203) Ethics Lacking in Business School Curriculum, Students Say in Survey New York Times 20 May 2003 p C3.

10. Enron's Code of Ethics (extract) from www.business ethics.ca/enron/index.html accessed 27 October 2005.

11. Frankena W. (1973) Ethics Prentice Hall Englewood cliffs NJ.

12. Freedman M. The Social responsibility of Business is to Increase Profits New York Times.

13. Giddens A. (1976) New Rules of Sociological Method, Hutchinson, London Berkley.

14. Giddens A. (1979) Central Problems in Social Theory: action, structure contradictions in social analysis Macmillan London; University of California Press, Berkley.

15. Giddens A. (1984) The Constitution of Society: outline of the theory of structuration University of California Press, Berkley.

16. Giddens A. (1990) Structuration Theory and Sociological Analysis in Clark J. Mogdil C. and Mogdil S eds Anthony Giddens: consensus and controversy Falmer, Basingstoke.

17. Hayek, F.A. (1982) Law, Legislation, and Liberty, Vol 2 the mirage of social justice Routledge \& Kegan Paul, London.

18. Kagan S. (1989) Normative Ethics Dimensions of Philosophy Series Westview Press Boulder Colorado.

19. Kolkata G. (2003) Ethics 101: a Course About the Pitfalls New York Times 21 October 2003 p 3.

20. McKenna R. (1999) New Management McGraw Hill Roseville New South Wales.

21. Smith A. (1976) A Inquiry in to the Wealth and Causes of the Wealth of Nations edited by Campbell R., Skinner a., and Todd W., Clarendon Press Oxford.

22. Soloman, R. (1994) Above the Bottom Line, Harcourt Brace, pp. 517-523.

23. Solomon, R. Morality: The Basic Rules in Hartman, L. (1998) Perspectives in Business Ethics, Irwin McGraw-Hill, Chicago.

24. Theis D. (1998) Should Ethics Be Taught in College? In Hartman L., Perspectives in Business Ethics McGraw Hill Chicago. 